\title{
Sensitivity of land surface and Cumulus schemes for Thunderstorm prediction
}

\author{
Kumar Dinesh*, Mohanty U.C. ${ }^{1}$, Kumar Krishan ${ }^{2}$ \\ *Assistant Professor, Department of Environmental Sciences, Central University of Jammu, Jammu, India \\ (dineshjnu2020@gmail.com), ${ }^{2}$ Emeritus Professor, School of Earth, Ocean and Climate Sciences, IIT Bhubneswar, \\ Orisha, India (ucmohanty@iitbbs.ac.in), ${ }^{3}$ Professor, School of Env Sciences, Jawaharlal Nehru University, New Delhi, \\ India(kklab301@gmail.com)
}

\section{Commission WG VIII/3}

\author{
KEY WORDS: Mesoscale, Parameterization, Microphysics, Grid-scale
}

\begin{abstract}
The cloud processes play an important role in all forms of precipitation. Its proper representation is one of the challenging tasks in mesoscale numerical simulation. Studies have revealed that mesoscale feature require proper initialization which may likely to improve the convective system rainfall forecasts. Understanding the precipitation process, model initial condition accuracy and resolved/sub grid-scale precipitation processes representation, are the important areas which needed to improve in order to represent the mesoscale features properly. Various attempts have been done in order to improve the model performance through grid resolution, physical parameterizations, etc. But it is the physical parameterizations which provide a convective atmosphere for the development and intensification of convective events. Further, physical parameterizations consist of cumulus convection, surface fluxes of heat, moisture, momentum, and vertical mixing in the planetary boundary layer (PBL). How PBL and Cumulus schemes capture the evolution of thunderstorm have been analysed by taking thunderstorm cases occurred over Kolkata, India in the year 2011. PBL and cumulus schemes were customized for WSM-6 microphysics because WSM series has been widely used in operational forecast. Results have shown that KF (PBL scheme) and WSM-6 (Cumulus Scheme) have reproduced the evolution of surface variable such as CAPE, temperature and rainfall very much like observation. Further, KF and WSM- 6 scheme also provided the increased moisture availability in the lower atmosphere which was taken to higher level by strong vertical velocities providing a platform to initiate a thunderstorm much better. Overestimation of rain in WSM-6 occurs primarily because of occurrence of melting and freezing process within a deeper layer in WSM-6 scheme. These Schemes have reproduced the spatial pattern and peak rainfall coverage closer to TRMM observation. It is the the combination of WSM- 6 , and KF schemes which have preformed reasonably well to reproduce the right atmospheric condition for a thunderstorm leading to improved spatial and temporal rainfall over the study domain. Thus the parameterization schemes of WMS-6 and KF have shown significant improvement by capturing the location, intensity and surface meteorological parameters closer to observed details.
\end{abstract}

\section{INTRODUCTION}

The cloud processes play an important role in all forms of precipitation. Its proper representation is one of the challenging tasks in mesoscale numerical simulation (Lin et al. 2006). Stensrud et al. (1994, 1999b) revealed in his study that mesoscale feature require proper initialization which may likely to improve the convective system rainfall forecasts. Model physics and initial condition play significant role in ensemble forecasting (Stensrud et al. 2000). Understanding the precipitation process, model initial condition accuracy and resolved/sub grid-scale precipitation processes representation, are the important areas which needed to improve in order to represent the mesoscale features properly (W. Wang et al. 1997). Various attempts have been done in order to improve the model performance through grid resolution, physical parameterizations, etc. But it is the physical parameterizations which provide a convective atmosphere for the development and intensification of convective events (Anthes, 1982). Further, physical parameterizations consist of cumulus convection, surface fluxes of heat, moisture, momentum, and vertical mixing in the planetary boundary layer (PBL). A wide variety of cumulus parameterization schemes (CP) have been developed and incorporated into mesoscale models (Arakawa et al. 1974; Fritschet al. 1980; Betts et al. 1986; Kain et al. 1993; Grell 1993). The cumulus parameterization can be verified by applying it on an environment other than tested by the developer because universal conceptual framework for cumulus schemes is not easy to frame (Arakawa 1993). In convective situations it is necessary to use such schemes in conjunction with a cumulus parameterization to avoid excessive grid-scale precipitation due to an unrealistic feedback between low-level heating, surface pressure fall, low-level moisture convergence, and upward motion (Zhang et al. 1988; Molinari et al.1992.).

$\mathrm{CP}$ schemes involve updrafts, downdrafts, entrainment of air and detrainment of air throughout the height of the atmosphere, including the boundary layer. Frank (1983) demonstrated the role of precipitating cumulus clouds in release of latent heat of condensation and its active involvement in freezing and melting phase changes over the region of conditional instability. Micro-physical characteristics of clouds are very much responsible for convection moistening of the atmosphere, which determine the convective water flux to the surface as precipitation and to humidify the atmosphere.

PBL schemes involve boundary layer fluxes, vertical diffusion, heat flux and frictional forces within the atmosphere. They also measure the mixing of air between layers of the atmosphere (Hong et al. 2006). Temperature and moisture profiles are significantly affected by the choice of planetary boundary layer (PBL) scheme in the lower troposphere, which could interact with convective parameterization to influence simulation of precipitation (e.g., Bright et al. 2002; Wisse et.al.2004). In recent years, it has been realized that the PBL is a defining factor (Braun et al. 2000) because large fluxes of heat, moisture, and momentum are generated in this thin layer. Therefore, 
several PBL parameterization schemes (PBLSs) have been incorporated in the NWP models (e.g., Mellor et al. 1982; Hong et al. 2006). With the availability of such a variety of parameterization schemes, it would be very important to perform sensitivity tests to understand the applicability of schemes for convective cases. Morrison et al. (2011) compared a one- and two-moment version of the same parameterization on the development of precipitation of an idealized squall line. Rajeevan et al. (2010) performed sensitivity tests on four different MP schemes for a thunderstorm event using WRF with multiple nested domains. Morrison and Milbrandt (2011) compared their respective schemes in a WRF idealized simulation of a supercell thunderstorm by running sensitivity tests for individual processes. Tao et al. (2011) tested the impact of four microphysical schemes on Hurricane Katrina.

This study has been undertaken to examine the performance of various convection and PBL schemes for thunderstorm cases observed over Kolkata. The study has been done to determine the most suited model parameterization schemes for the simulation of thunderstorm over Indian region. two thunderstorm events that occurred over the Kolkata on 18May (cases-1), 25 May (case-2), 2011 respectively are considered.

\subsection{Modelling system}

A high resolution, mesoscale, numerical weather prediction (NWP) model, Advance Research Weather Research and Forecasting WRF_ARW) is used for the present research work. ARW is a comprehensively documented state-of-the-art, supported as a community model to facilitate world-wide use, for research, operations, and teaching. It is suitable for a broad spectrum of applications across various scales ranging from micro to global scale simulations. As of now, many countries and institutions are using ARW model to serve their operational and research needs. A useful feature about the ARW modeling system is its flexibility in terms of many options that are user specified. The ARW dynamical core uses Eulerian finite differencing to integrate the fully compressible non-hydrostatic equations in mass-coordinate, scalar conserving flux form using a time-split small step for acoustic modes. Large time steps utilized a third-order Runge-Kutta technique. The horizontal staggering is an Arakawa-C grid. It has four types of map projections such as Mercator (low latitudes), Lambert conformal (mid latitudes), polar stereographic (poles) and rotated lat-long projections. The ARW model has different physics options, each having many choices; to represent the physical processes for real-data mesoscale forecasts. The physics involved in this model are (i) microphysics schemes, (ii) cumulus convective parameterizations, (iii) planetary boundary layer (PBL) parameterizations, (iv) land surface model (LSM), (v) surface layer parameterization schemes and (vi) radiation schemes. A detailed description of the model governing equations, its physics, vertical coordinate system, and its dynamics is available in Skamaraock, et al, (2005).

\subsection{Synoptic Overview \\ 18 May2011 (Case-1):}

An examination of plots obtained from NCEP FNL data at 00 UTC of 18 May 2011 indicates an elongated low pressure area which extends from north Pakistan to west Uttar Pradesh and a trough from this running through Bihar and Jharkhand. An upper air circulation over UP, West Bihar and neighbourhood is seen in lower levels. Another trough is seen over AP which is extended up to Arabian Sea joined by another cyclonic circulation. These cyclonic system influences the development of local convective echoes over north WB at 2UTC which moved south-east direction. These convective echoes further intensified and reached over Kolkata at 4UTC and resulted into moderate rainfall of $3.8 \mathrm{~mm}$. Further this system dissipated at 5UTC over Kolkata. Another convective system were also developed at 18UTC and dissipated at 23UTC.

\section{May2011 (Case-II):}

Surface pressure plots obtained from NCEP FNL data at 00 UTC of 25 May 2011 has shown the extension of low pressure area much similar like as in 18 May which extends from north Pakistan to west Uttar Pradesh and a trough from this running through Bihar and Jharkhand up to Head Bay. An upper air cyclonic circulation over Assam and neighbourhood is seen in lower levels. Another upper air cyclonic circulation over central Pakistan and adjoining northwest Rajasthan is seen in lower levels. A trough from this system extends up to Gangetic West Bengal across Haryana, Uttar Pradesh and Jharkhand. Another upper air cyclonic circulation lies over Gangetic West Bengal and neighbourhood which extend up to $3.1 \mathrm{Km}$ above mean sea level. Further, a north-south trough from south Chhattisgarh to south Tamilnadu is observed in the lower levels. The sub tropical westerly jet stream lies over the Tibetan plateau which is far north of the study domain.

Convective echoes were noticed at about 200$250 \mathrm{Km}$ northeast of Kolkata in the images of Doppler Weather Radar (DWR) at Kolkata at 1100 UTC which later intensified into a northwest -southeast oriented squall line spanning about $150-200 \mathrm{~km}$ by 1500 UTC . It further moved south/south eastwards and dissipated by 1700 UTC. Further, light rain occurred at Kolkata $(12.8 \mathrm{~mm})$, Canning $(18.6 \mathrm{~mm})$, Basirhat (19.8) and very light rain occurred at Kalaikunda (3.4mm), Midnapore (1mm) and Kharagpur (1mm).

\section{Experimental Designing}

Microphysics, cumulus schemes along with LS schemes of WRF model used for a number of thunderstorm cases are provided in Table for the sensitivity experiments over North Eastern Indian region. A series of four experiments were carried out for related combinations of cumulus and Land surface schemes. The names and scheme combinations of these four experiments are provided in Table-1. All the experiments were initialized with National centers for environmental prediction (NCEP) FiNaL (FNL) analyses data (in 6-h interval of $1^{\circ} \times 1^{\circ}$ horizontal resolution). The model was initialized at 00 UTC and integrated for 24 hours.

\begin{tabular}{|l|l|l|l|}
\hline Table-1: List of Experimental Combination \\
\hline S No. & MP & LS & CU \\
\hline 1 & \multirow{2}{*}{ ETA } & \multirow{2}{*}{ NOAH } & KF \\
\cline { 4 - 4 } & & GD \\
\hline 3 & \multirow{2}{*}{ WSM-6 } & $\begin{array}{l}\text { Thermal } \\
\text { Diffusion (TD) }\end{array}$ & KF \\
\hline 4 & & GD \\
\hline
\end{tabular}

\section{Results and Discussion}

Mesoscale atmospheric models depend on land surface schemes to provide surface fluxes of heat, moisture, and momentum from the surface to the atmosphere. It is found that the rainfall amounts are sensitive to the choice of convective parameterization and to the land surface characteristics. The land use/land cover sensitivity tests showed that land surface feedback results in broader areal and dynamical impacts on rainfall intensity and distribution (Chang et al; 2007). Thermal diffusion and NOAH schemes are chosen for land surface parameterization considering four thunderstorm cases. It might 
be important to mention here that land surface parameterization has more impact on the surface fluxes which affect further development of lower atmospheric boundary layer.

\subsection{Progression of CAPE, (2m) temperature and rainfall:}

Fig-1 illustrates the time series of thermodynamic stability indices such as Convective Available Potential Energy (CAPE); and temperature for case-1 and case-2 over Kolkata. Time series show that CAPE in NOAH scheme shows good agreement with observed CAPE. In case- 1 and case- 2 , the NOAH scheme could simulate the maximum CAPE of about $3978 \mathrm{~J} \mathrm{~kg}-1$ and $2982, \mathrm{~J} \mathrm{~kg}-1$ at 6 UTC and 12 UTC respectively. It is notable here that NOAH scheme captures the unstable atmospheric development with high CAPE providing the platform to develop the severe convection.

Rainfall time series has been provided in Fig-3. Rain in the range of $3 \mathrm{~mm}$ at $5 \mathrm{UTC}$ and $13 \mathrm{~mm}$ at $15 \mathrm{UTC}$ were recorded in case- 1 and in case- 2 respectively. It is seen from fig-3that NOAH has improved the initiation of convection occurrence closer to observation. Further, Noah scheme has also improved the intensity and time lag in both cases as compared to TD scheme. Similarly, temperature drop after the rainfall at 5UTC and 15UTC in case- 1 and case-2 respectively were reproduced better in $\mathrm{NOAH}$ scheme and its progression similar to observation was also improved in NOAH experiment as compared to TD scheme.

\subsection{Evolution of vertical velocity, moisture convergence} and mixing ratio:

Time-height progression of (a) Vertical Velocity $(\mathrm{cm}$ $\left.\mathrm{s}^{-1}\right)$ and (b) mixing ratio $\left(\mathrm{g} \mathrm{kg}^{-1}\right)$ over Kolkata for both the cases for NOAH and TD scheme has been provided in fig- 2 . The NOAH scheme, in time-height evolution of vertical velocity for the both cases, has produced strong updraft as compared to TD scheme. Moreover, NOAH has shown a updraft in the range of $300 \mathrm{~cm} \mathrm{~s}^{-1}$ at 7UTC and $200 \mathrm{~cm} \mathrm{~s}^{-1}$ at 9UTC in case-1 and case- 2 respectively. It is evident that vertical velocities are shown closer to observed convection time better in NOAH scheme. With the availability of increased soil moisture in NOAH scheme, it may have resulted in more moisture in the lower atmosphere.

The model has simulated moisture at the lower atmosphere in both the schemes but, moisture peak at the time of respective convection i.e. 8UTC and 9UTC is more pronounced in NOAH scheme. Though, moisture is simulated at lower atmosphere at 6-12UTC in both schemes, NAOH has improved the intensity and moisture availability at the right time in both the cases. Low level moisture accompanied with strong upward vertical velocity strengthens the possibility of thunderstorm occurrence in an unstable atmosphere. These features of vertical unstable warm air column in NOAH has improved probably due to combined effect of surface fluxes of sensible and latent heat exchange from the underlying warm land surface and the strong updrafts in thunderstorm region.
Case-1
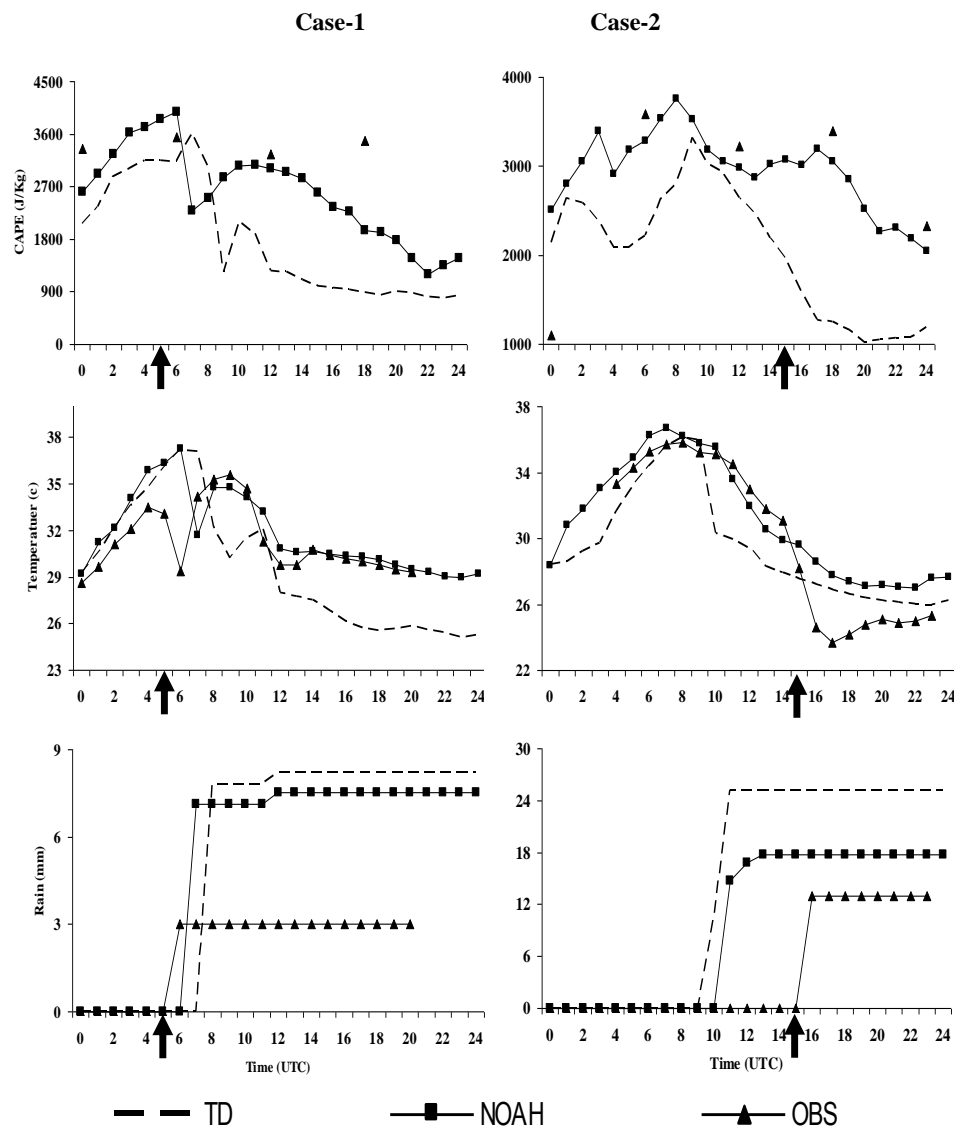

Fig-1:Temporal Evolution of (a) CAPE (J/Kg-1), (b) $2 \mathrm{~m}$ temperature (c) and (c) rainfall (mm) over Kolkata for case-1 and case- 2 for NOAH and TD scheme. Arrow indicates the time occurrence of thunderstorm.
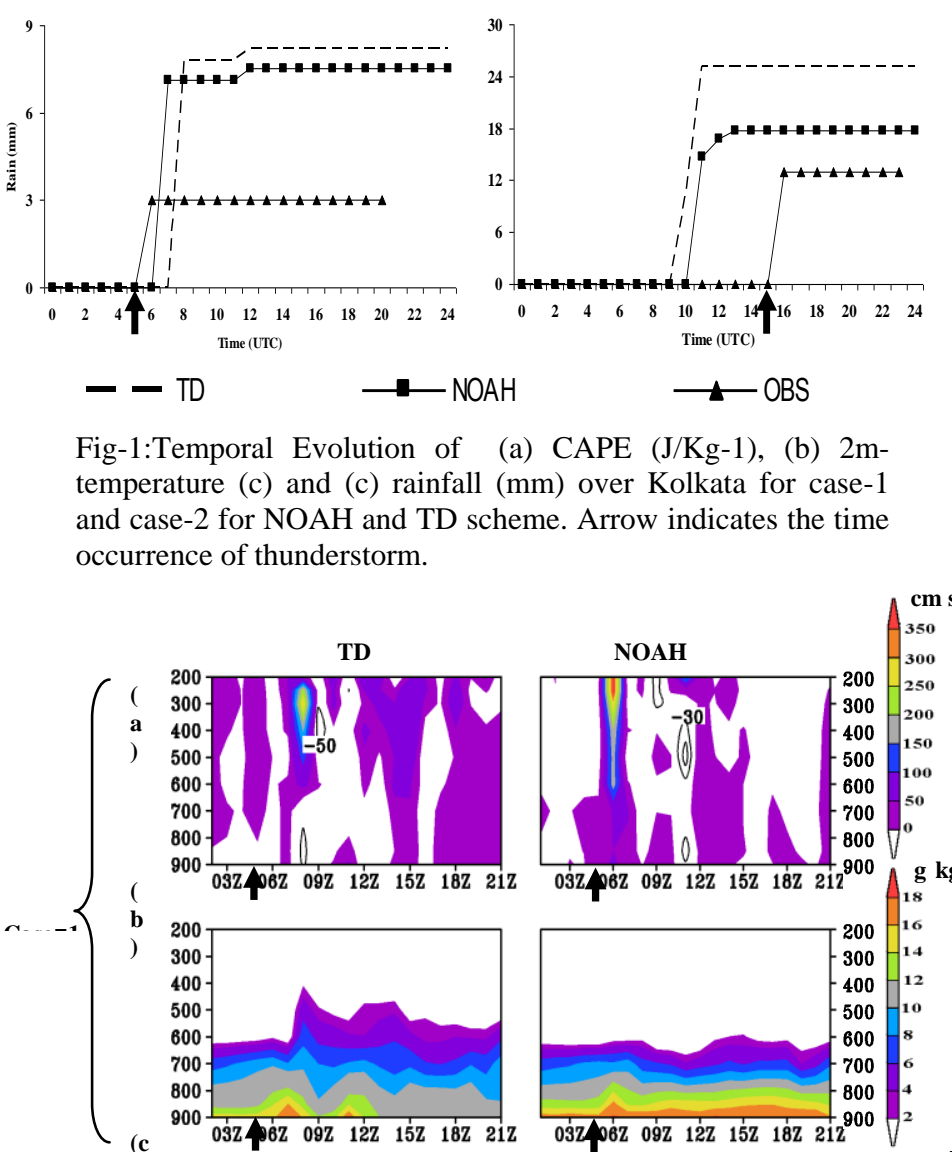

Case-2 $\left\{\begin{array}{l})^{c} \\ ( \\ \text { d }\end{array}\right.$
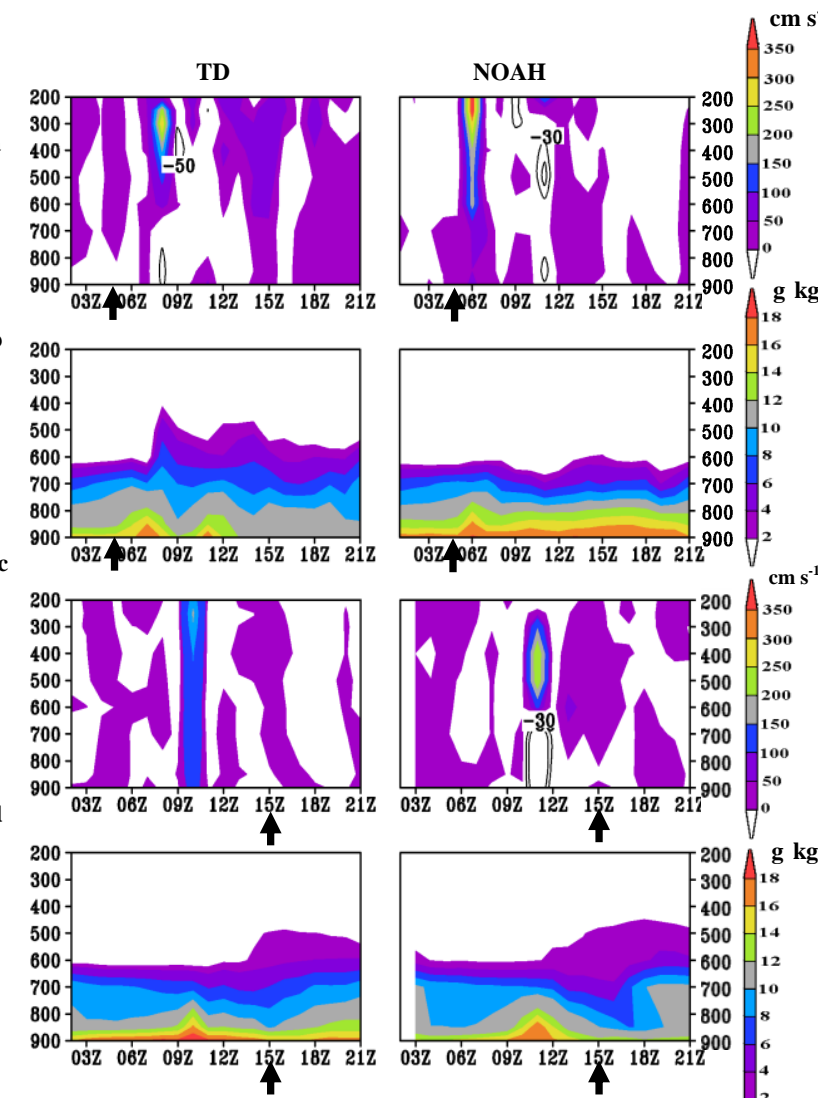

$\mathrm{cm} \mathrm{s}^{-1}$

350

$-300$

\section{$\mathrm{kg}^{-}$}

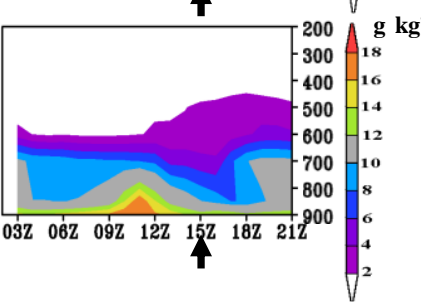

Fig-2: Height-time progression of (a) Vertical Velocity (cm s-1) and (b) mixing ratio (g kg-1) over Kolkata for case-1 for NOAH and TD scheme. (c) and (d) are the same as (a) and (b) but for case-2. Arrow indicates the time occurrence of thunderstorm. 


\subsection{Simulation of surface precipitation:}

Fig-3 presents TRMM observation along with six hourly simulated accumulated rainfall during the thunderstorm occurrence. It is observed in TRMM that maximum rainfall is located over Bangladesh and WB. Maximum rain of $45 \mathrm{~mm}$ over Bangladesh and WB were seen in case-1, while most of the rain $(45 \mathrm{~mm})$ was observed over Bangladesh only. Spatial distribution of the rainfall is simulated well in both the schemes. However, NOAH has captured the intensity and spatial pattern better which is much closer to TRMM observation.
TD

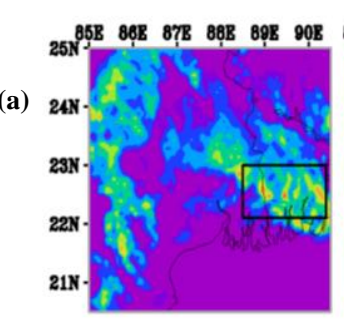

(b)

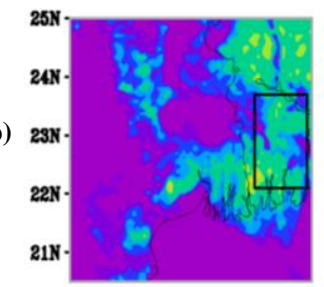

NOAH
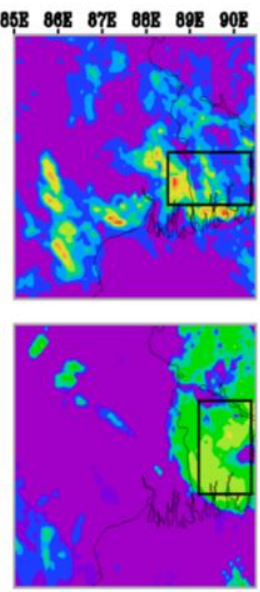

TRMM

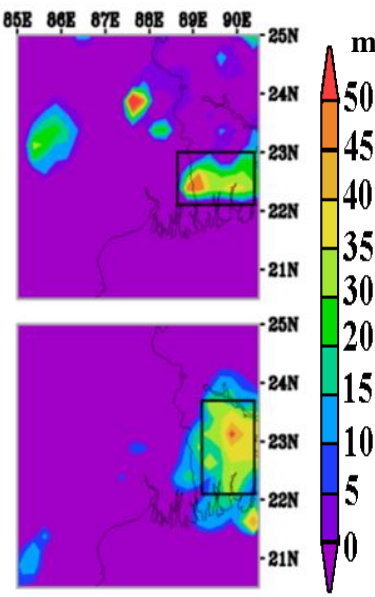

Fig-3: six-hourly accumulated rainfall (mm) along with TRMM observed rainfall during severe thunderstorm event for (a) case-1 (12UTC-18UTC), (b) case-2 (6UTC-12UTC), (c) case-3 (0UTC6UTC) and (d) case-4 (0UTC-6UTC).

\section{Conclusion:}

Analysis of sensitivity experiments using different physical parameterization schemes are concluded for cumulus and land surface schemes here. Land surface schemes (models) provide the surface fluxes of heat, moisture, and momentum to the atmosphere. From the analysis it has been observed that surface analysis in terms of CAPE, temperature and surface fluxes in NOAH shows most probable evolution or good agreement with observation. Surface fluxes analysis has shown that NOAH has provided more surface moisture and decreased surface temperature. Increased latent heat and decreased sensible heat flux are more pronounced in NOAH due to increased soil moisture and decreased soil temperature. The better surface fluxes exchange in NOAH have evolved the lower atmosphere having high CAPE and increased temperature which have turned into a platform to develop the severe convection. Vertical structure of the air column over Kolkata have got the significant moisture at lower level due to improved surface fluxes in NOAH which started developing suitable condition for thunderstorm with the help of strong vertical velocities. Further, it is noted that NOAH has improved the initiation of convection occurrence and reproduced reasonable good rain intensity closer to observation. Moreover, rainfall pattern were improved significantly over the domain and came closure to TRMM.

Above analysis may be concluded as the combination of WSM-6, and KF schemes along with NOAH land surface scheme have preformed reasonably well to reproduce the right atmospheric condition for a thunderstorm leading to improved spatial and temporal rainfall over the study domain.
Acknowledgements: This work is supported through a financial support from Council of Science and Industrial Research (CSIR). We thank the India Meteorological Department (IMD) for providing the observations for model validation. The authors gratefully acknowledge the NCEP/NCAR for providing FNL analyses and satellite radiance datasets for the present study.

\section{References:}

Anthes, R.A., 1982. Tropical cyclones-their evolution, structure, and effects. Monograph No. 41, American Meteorological Society.

Arakawa, A., 1993. Closure assumptions in the cumulus parameterization problem. The Representation of Cumulus Convection in Numerical Models, Meteor. Monogr. No. 46,Amer. Meteor. Soc. 1-15.

Arakawa, A., Schubert, W. H., 1974. Interaction of a cumulus cloud ensemble with the largescale environment. Part I. J Atmos Sci. 31, 674-701.

Braun, S. A., Tao, W. K., 2000. Sensitivity of high-resolution simulations of hurricane Bob (1991) to planetary boundary layer parameterizations. Mon Weather Rev. 128:3941-3961.

Bright, D. R., Mullen, L. S., 2002. The Sensitivity of the Numerical Simulation of the Southwest Monsoon Boundary Layer to the Choice of PBL Turbulence Parameterization in MM5, Weather and Forecasting. Vol 17, 99-114.

Chang, H. I., Kumar, A., Niyogi, D., Mohanty, U.C., Chen, F., Dudhia, J., 2007. Impact of Physical Parameterization and Land use Land Cover change on the simulation of the July 26, 2005 heavy rain event over Mumbai, Indai, 21th conference on Hydrology.AMS Annual meeting, 15 -18 January 2007, San Antonio, TX.

Frank, W. M., 1983. The cumulus parameterization problem. Mon. Wea. Rev. 111, 1859-1871.

Hong, S. Y., Lim, J. O. J., 2006. The WRF Single-Moment 6Class Microphysics scheme (WSM6), Journal of the Korean Meteorological Society. 42, 2 129-151.

Mellor, G. L., Yamada, T., 1982. Development of a turbulence closure model for geophysical fluid problems. Rev. Geophys. Space Phys. 20, 851-875.

Molinari, J., Dudek, M., 1992. Parameterization of convective precipitation in mesoscale numerical models: A critical review. Monthly Weather Review. 120, 326-344.

Morrison, H., Milbrandt, J., 2011. Comparison of Two-Moment Bulk Microphysics Schemes in Idealized Supercell Thunderstorm Simulations. Monthly Weather Review. 139, 1103-1130.

Rajeevan, M., Kesarkar, A., Thampi, S. B., Rao, T. N., Radhakrishna, B., Rajasekhar, M.,2010. Sensitivity of WRF cloud microphysics to simulations of a severe thunderstormevent over Southeast India. Annales Geophysicae. 28, 603-619. 
Skamarock, W. C., Klemp, J. B., Gill, D. O., Barker, D. M., Powers, J. G., 2005. A Description of the Advanced Research WRF Version 2.

Stensrud, D. J., Wandishin, M. S., 2000. The correspondence ratio in forecast evaluation. Wea.Forecasting. 15, 593-602.

Tao, W. K., Shi, J. J., Chen, S. S., Lang, S., Lin, P. L., Hong, S. Y., Peters-Lidard, C., Hou,A., 2011. The Impact of Microphysical Schemes on Hurricane Intensity and Track. AsiaPacific J. Atmos. Sci. 47, 1-16, doi:10.1007/s13143-011-1001$\mathrm{z}$.

Wang, W., Seaman, N. L., 1997. A comparison study of convective parameterization schemesin a mesoscale model. Mon. Weather Rev. 125, 252-278.

Zhang, E. Y. H., Moncrieff, M. W., 1988. A comparison of explicit and implicit predictions of convective and stratiform precipitating weather systems with a meso-b-scale numerical model. Quart. J. Roy. Meteor. Soc. 114, 31-60. 